\title{
Road Traffic Accident Analysis and Identification of Black Spot Locations on Highway
}

\author{
Asad Iqbal ${ }^{a^{*}}$, Zia ur Rehman ${ }^{b}$, Shahid Ali ${ }^{c}$, Kaleem Ullah ${ }^{\text {a }}$, Usman Ghani ${ }^{\mathrm{c}}$ \\ ${ }^{a}$ The University of Lahore, Lahore, 54000, Pakistan. \\ ${ }^{b}$ University of Engineering \& Technology, Lahore, 54000, Pakistan. \\ ${ }^{c}$ National University of Computer and Emerging Sciences, Lahore, 54000, Pakistan.
}

Received 26 August 2020; Accepted 19 November 2020

\begin{abstract}
Road safety is the main problem in developing countries. Every year, millions of people die in road traffic accidents, resulting in huge losses of humankind and the economy. This study focuses on the road traffic accident analysis and identification of black spots on the Lahore-Islamabad Highway M-2. Official data of road traffic accidents were collected from National Highway and Highway Police (NH \& MP) Pakistan. The data was digitized on MS Excel and Origin Pro. The accident Point weightage (APW) method was employed to identify the black spots and rank of the top ten black spots. The analysis shows that the trend of road traffic accidents on M-2 was characterized by a high rate of fatal accidents of $35.3 \%$. Human errors account for $66.8 \%$ as the major contributing factors in road traffic accidents, while vehicle errors $(25.6 \%)$ and environmental factors $(7.6 \%)$ were secondary and tertiary contributing factors. The main causes of road traffic accidents were the dozing on the wheel (27.9\%), the careless driving (24.6\%), tyre burst (11.7\%), and the brakes failure (7.4\%). Kallar Kahar (Salt Range) was identified as a black spot (223 km, 224 km, 225 km, 229 $\mathrm{km}$, and $234 \mathrm{~km}$ ) due to vehicle brake failure. The human error was a major contributory factor in road traffic accidents, therefore public awareness campaign on road safety is inevitable and use of the dozen alarm to overcome dozing on the wheel.
\end{abstract}

Keywords: Road Traffic Collisions; Highway; Black Spots; Safety; Fatal; Injuries; Collision Point Weightage.

\section{Introduction}

Road traffic collisions, and specifically highway-vehicle collisions, cost the lives of roughly one and a quarter million people worldwide every year. Furthermore, highway-traffic injuries are globally the primary cause of death among people of 15 to 29 years old with over three million deaths [1]. Approximately 1.3 million people die each year due to road collisions and 50 million people injured around the world [2]. From a policy and engineering viewpoint, maybe the most stimulating element of these numbers is their perseverance and the incapability of advanced vehicle safety features, advances in highway design, and various security countermeasures policies to extremely reduce these numbers [3]. It is estimated that the total number of casualties resulting from road collisions will increase by about $65 \%$ between 2000 and 2020. In developing and underdeveloped republics, this number is expected to be $80 \%$ [4]. The economic loss is around US $\$ 65$ billion, while in high-income countries it is around the US $\$ 518$ billion a year in developing countries [5]. The injuries caused by road collisions would show an increase in value. By 2030, it will become the fifth-largest source of mortality and, in addition to the concerns of middle-income and low-income

* Corresponding author: asadcivil03@gmail.com

http://dx.doi.org/10.28991/cej-2020-03091629

(C) 2020 by the authors. Licensee C.E.J, Tehran, Iran. This article is an open access article distributed under the terms and conditions of the Creative Commons Attribution (CC-BY) license (http://creativecommons.org/licenses/by/4.0/). 
countries, nearly $90 \%$ of global deaths have occurred on the roads [6]. Road traffic collisions between the two or more vehicles, between the pedestrians and vehicle, between the vehicles and fixed obstacles [7]. The black spot of the collision refers to a segment or section of road considered to be a place with a high risk of road collisions [8, 9]. Another description of the black spot is that any site or location is $100 \mathrm{~m}$ in length and the past five years, four bodily injuries have been noted [10]. In Sub-Saharan Africa, more people die due to road traffic collisions as compared to many other dangerous diseases, mostly those aged between 15 to 29 years. Approximately six people die daily due to road traffic collisions in Ghana [11].

Normally, there are three types of road user which involved in road collisions are vehicle, cyclists, pedestrians, and passengers. Few factors have been involved in recent years are driver, vehicle, pavement, and environment which causes collisions [12]. There are many types of harm or consequence, but the top three factors that matter most in traffic collisions are deaths, injuries, and property damage $[12,13]$. The severity index is defined as the ratio between the number of deaths and the total number of collisions [14]. Furthermore, road collisions show that extreme weather affects the occurrence of road collisions. The road collisions keep on comparatively constant and high for the period of 9:00 AM to 9:00 PM and variable but low during mid-night and early hours of the day. However, this does not imply that daytime driving is riskier than nighttime driving. There are several factors responsible for collisions but the drivers' fault is found to be the most important one; drivers' fault accounted for 78\% of total collisions in 2013 [15]. About 54\% of drivers were involved in road collisions during the years of 2003 to 2005 in the United Kingdom [16]. The researcher concluded that 33\% collisions occurred on a straight road, $31 \%$ on little curved and $19 \%$ on curved and also $51 \%$ collision occurred in dry weather, cold /icy (32\%), rainy (13\%), and cloudy (6\%). The study in Kenya showed $85 \%$ of the collisions were caused by human factors [7]. The maximum 18\% collision occurred in July. The fatalities rate was $23 \%$ and vehicle car (31\%) was involved in collisions [17]. The collision mostly happened during the time of 16:00 to 18:00 and driving to close (head-on collision) is the main cause of collisions [18].

Pakistan is a developing country and faces many problems related to traffic safety. 0.048 million people died and 0.097 million people were injured in various road collisions during 2006 and 2014 in the country [19]. According to the survey, in 2000, the total number of motor vehicles registered was 4.7 million. In 2015, the total number of registered vehicles amounted to 17.31 million in this country; a massive increase, and more than $268 \%$ of motor vehicles have been registered for 15 years [20]. This country is a developing country of the South Asian region having the world's sixth-largest population of over 200 million [1]. The vehicle population of the country has fully-fledged as a comparison to the economy and road infrastructure [21,22]. The economic budget of road injuries and crashes is projected to be over 100 billion rupees in the region [22,23]. Table 1 shows that the number of collisions has increased as compared to previous years in the country [24]. The results indicated that in accordance with the accident severity model in 2016 ,

Several factors such as the season of autumn, daytime light, drivers aged from 18 to 60 , and pickup trucks have impacted the on-road freight accident severity. While, in 2017 the severity was affected by factors like rural road, freight trucks, non-faulty passenger cars, motorcycles, and pedestrians [27].

Table 1. Road traffic collisions statistics of Pakistan (2008-2017)

\begin{tabular}{cccccc}
\hline \multirow{2}{*}{ Year } & $\begin{array}{c}\text { Total number of } \\
\text { collisions }\end{array}$ & \multicolumn{2}{c}{ Collision } & \multicolumn{2}{c}{ Persons } \\
\cline { 3 - 6 } & 9496 & 4145 & 5351 & 4907 & 11037 \\
\hline $2008-09$ & 9747 & 4378 & 5369 & 5280 & 11173 \\
$2009-10$ & 9723 & 4280 & 5443 & 5271 & 11383 \\
$2010-11$ & 9140 & 3966 & 5174 & 4758 & 10145 \\
$2011-12$ & 8988 & 3884 & 5104 & 4719 & 9710 \\
$2012-13$ & 8359 & 3500 & 4859 & 4348 & 9777 \\
$2013-14$ & 7865 & 3214 & 4651 & 3954 & 9661 \\
$2014-15$ & 9100 & 3591 & 5509 & 4448 & 11544 \\
$2015-16$ & 9582 & 4036 & 5546 & 5047 & 12696 \\
$2016-17$ & 11121 & 4829 & 6292 & 5948 & 14489 \\
$2017-18$ & & & & & \\
\hline
\end{tabular}

With the above information and data assessment, very little study has been carried out yet in Pakistan. Therefore, in this research, analysis of road traffic collision data is accomplished to determine the causes of collisions on highway and identification of black spots locations on Lahore-Islamabad Highway M-2. 


\section{Materials and Methods}

\subsection{Data Collection}

Collision data of M-2 from 2009 to 2017 were collected from National Highway and Highway Police (NH \& MP) by ethical permission. The length of the Highway is $353 \mathrm{~km}$ and divided into different beats and sections. This highway was completed in 1997 as a six-lane highway (three lanes on each side) with total pavement width of $33 \mathrm{~m}$. It connects the two major cities Lahore and Islamabad. The speed allowed for light traffic is $120 \mathrm{~km} / \mathrm{h}$ and $90-110 \mathrm{~km} / \mathrm{h}$ for heavy traffic. The NH \& MP has a developed Road Traffic Collision (RTA) Performa which contain the with following details:

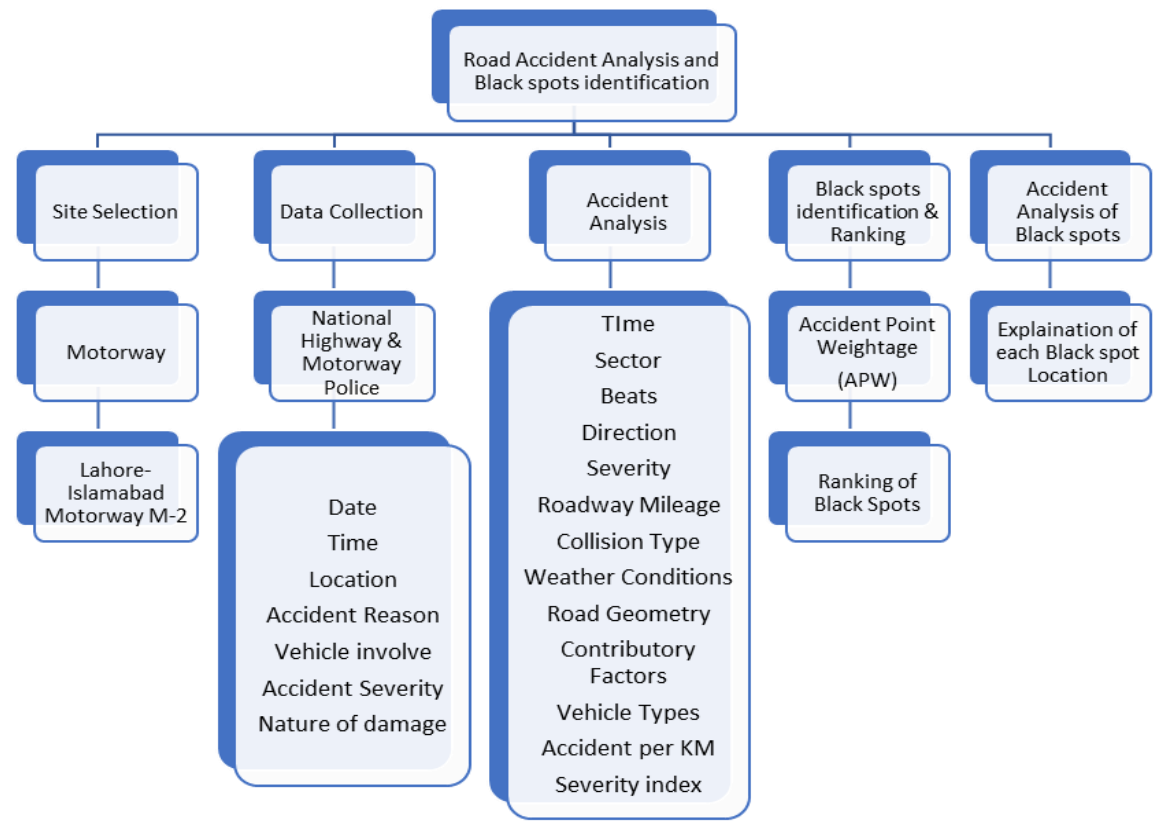

Figure 1. Flow Chart of Research Methodology

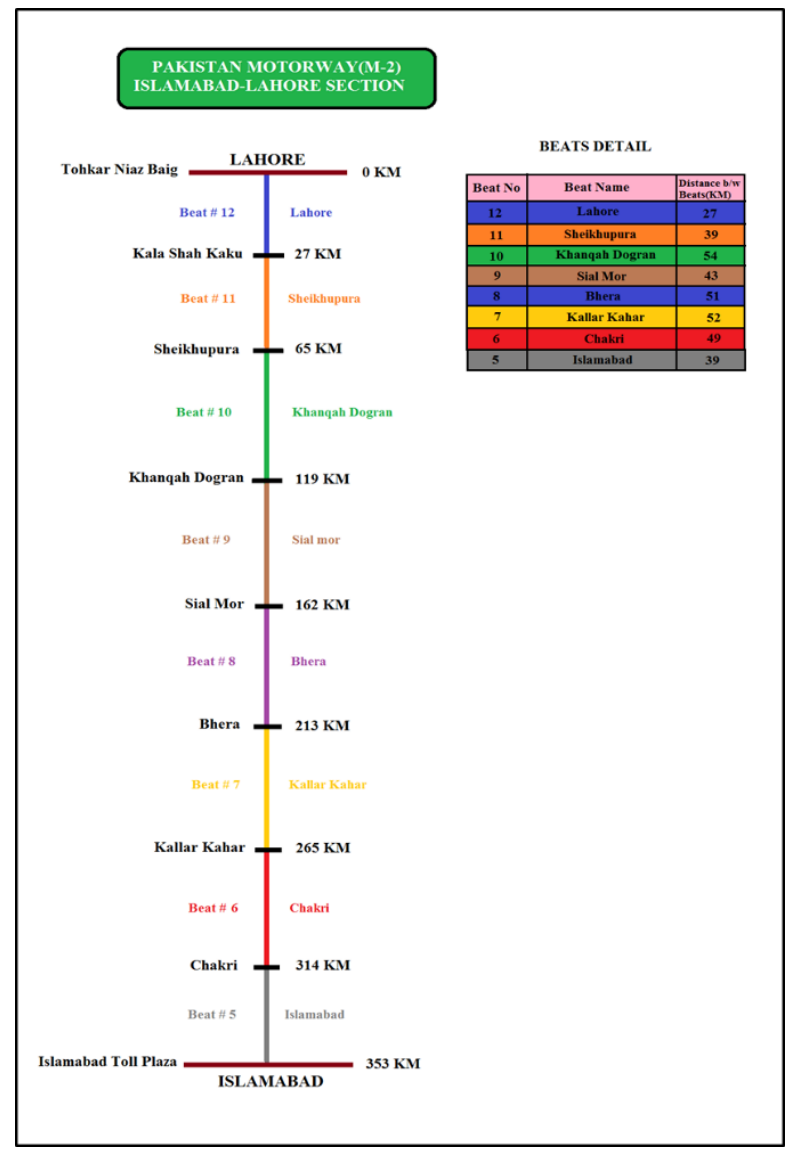

Figure 2. Study area map 
i. Date of Collision

ii. Time of Reporting

iii. Location

iv. Reason of Collision

v. Vehicles Involved

vi. Collision severity (fatality, major injury, minor injury, and property damage)

vii. Nature of Damage to Vehicle

Accident analysis data is used to detect the safety complications that might occur at a specific location. It could be used to detect the accident at a location, from where the probable reasons are recognized and identification of probable corrective actions

\subsection{Data Analysis}

Different researchers describe methods and models for calculating black spots on roads. The researchers have developed a classification of black spots of road collisions using the Collision Point Weightage (APW). After calculating APW, the top ten ranks were selected to identify black spots. The equation is given below [25, 26].

$\mathrm{APW}=6(\mathrm{~A})+3(\mathrm{~B})+0.8(\mathrm{C})+0.2(\mathrm{D})$

Where: $\mathbf{A}=$ number of fatal collisions, $\mathbf{B}=$ number of major injury collisions, $\mathbf{C}=$ number of minor injury collisions, $\mathbf{D}=$ number of property-damage collisions.

The methodology adopted in the research is as under:
i. Site Selection
ii. Data collection
iii. Data Analysis
iv. Black spots identification
v. Ranking

\subsection{Data Processing and Analysis}

The road traffic collision data were entered and digitized in MS Excel and Origin Pro software's. The collision Point Weightage (APW) method was employed to identify the black spots and ranking of the top ten black spots.

\section{Results and Discussion}

\subsection{Road Traffic Collision Analysis}

The summary of collision analysis is shown in Table 2, it shows that the highest number of road traffic collisions occurred in 2015 (22.4\%) and the lowest in 2014(7.6\%). The severity index (1.089) is maximum in 2017 and a minimum $(2.7 \%)$ in 2015 . The road traffic collisions occurred mostly in July (10.6\%) and least in January (5.7\%). Road traffic collisions are normally higher on Sunday (16.2\%) and lower on Monday (13.3\%). Most road traffic collisions took place at night time $(53 \%)$ and daytime $(47 \%)$. The trend of a road traffic collision is higher in early morning time 2:00-6:00 hours (13.9\%) and lowers in day time 10:00-14:00 hours (11\%). The severity of road traffic collisions categorizes collision as Fatal (35.3\%), Major (38.3\%), and Minor $(15.1 \%)$, and property damage only $(11.3 \%)$ occurred. Nose to tail road traffic collisions $(50.9 \%)$ and rollover $(31 \%)$ categorized the highest collisions in collision type analysis. As for weather and road geometry were concerned, most road traffic collisions occurred in dry weather $(92.4 \%)$ on straight roads $(98.8 \%)$. The contributory factors leading to road traffic collisions were human $(66.8 \%)$, vehicle $(25.6 \%)$, and environmental $(7.6 \%)$. The main causes of road traffic collisions were dozing on the wheel $(27.9 \%)$, careless driving $(24.9 \%)$, and tyre burst $(11.7 \%)$. As for a vehicle type fault in road traffic collisions, passenger cars $(37.2 \%)$ were mostly involved in road traffic collisions. 
Table 2. Road Traffic Collision Analysis of Lahore-Islamabad Highway (2009-2017)

\begin{tabular}{|c|c|c|c|}
\hline \multirow{2}{*}{ Variables } & \multirow{2}{*}{ Categories } & \multicolumn{2}{|c|}{ Frequency of Road Traffic Collisions } \\
\hline & & $\mathbf{N}$ & $\%$ \\
\hline \multirow{9}{*}{ Years } & 2009 & 95 & 7.8 \\
\hline & 2010 & 96 & 7.9 \\
\hline & 2011 & 112 & 9.2 \\
\hline & 2012 & 114 & 9.4 \\
\hline & 2013 & 98 & 8.1 \\
\hline & 2014 & 92 & 7.6 \\
\hline & 2015 & 272 & 22.4 \\
\hline & 2016 & 233 & 19.2 \\
\hline & 2017 & 101 & 8.3 \\
\hline \multirow{12}{*}{ Months } & Jan & 69 & 5.7 \\
\hline & Feb & 81 & 6.7 \\
\hline & Mar & 118 & 9.7 \\
\hline & Apr & 104 & 8.6 \\
\hline & May & 118 & 9.7 \\
\hline & Jun & 107 & 8.8 \\
\hline & Jul & 129 & 10.6 \\
\hline & Aug & 104 & 8.6 \\
\hline & Sep & 100 & 8.2 \\
\hline & Oct & 86 & 7.1 \\
\hline & Nov & 88 & 7.3 \\
\hline & Dec & 109 & 9.0 \\
\hline \multirow{7}{*}{ Days } & Mon & 161 & 13.3 \\
\hline & Tue & 170 & 14.0 \\
\hline & Wed & 165 & 13.6 \\
\hline & Thu & 171 & 14.1 \\
\hline & Fri & 171 & 14.1 \\
\hline & Sat & 179 & 14.8 \\
\hline & Sun & 196 & 16.2 \\
\hline \multirow{12}{*}{ Time } & 00:00-1:59 & 118 & 9.7 \\
\hline & $2: 00-3: 59$ & 121 & 10.0 \\
\hline & $4: 00-5: 59$ & 169 & 13.9 \\
\hline & $6: 00-7: 59$ & 103 & 8.5 \\
\hline & 8:00-9:59 & 94 & 7.7 \\
\hline & 10:00-11:59 & 66 & 5.4 \\
\hline & $12: 00-13: 59$ & 71 & 5.9 \\
\hline & 14:00-15:59 & 83 & 6.8 \\
\hline & $16: 00-17: 59$ & 103 & 8.5 \\
\hline & 18:00-19:59 & 97 & 8.0 \\
\hline & 20:00-21:59 & 95 & 7.8 \\
\hline & 22:00-23:59 & 93 & 7.7 \\
\hline \multirow{2}{*}{ Day/Night } & Day & 580 & 47.8 \\
\hline & Night & 633 & 52.2 \\
\hline \multirow{4}{*}{ Severity } & Fatal & 428 & 35.3 \\
\hline & Major & 465 & 38.3 \\
\hline & Minor & 183 & 15.1 \\
\hline & PDO & 137 & 11.3 \\
\hline
\end{tabular}




\begin{tabular}{|c|c|c|c|}
\hline \multirow{7}{*}{ Collision Type } & Roll over & 376 & 31.0 \\
\hline & Nose to Tail & 618 & 50.9 \\
\hline & Side Swipe & 36 & 3.0 \\
\hline & Pedestrian & 58 & 4.8 \\
\hline & Obstacle & 26 & 2.1 \\
\hline & Head-on & 48 & 4.0 \\
\hline & Other & 51 & 4.2 \\
\hline \multirow{15}{*}{ Causes } & Brake failure & 90 & 7.4 \\
\hline & Careless driving & 298 & 24.6 \\
\hline & Dozing at wheel & 339 & 27.9 \\
\hline & Improper crossing & 59 & 4.9 \\
\hline & Improper stoppage & 16 & 1.3 \\
\hline & Over speed & 67 & 5.5 \\
\hline & Tailgating & 5 & 0.4 \\
\hline & Wrong $\mathrm{U}$ turn & 7 & 0.6 \\
\hline & Passenger Fault & 5 & 0.4 \\
\hline & slippery Road & 54 & 4.5 \\
\hline & Tyre Brust & 142 & 11.7 \\
\hline & Bad weather & 33 & 2.7 \\
\hline & Wrong Parking & 2 & 0.2 \\
\hline & Mechanical Fault & 66 & 5.4 \\
\hline & other & 30 & 2.5 \\
\hline \multirow{4}{*}{ Road Geometry } & Straight & 1198 & 98.8 \\
\hline & Curve & 5 & 0.4 \\
\hline & Gradient & 4 & 0.3 \\
\hline & Curve and Gradient & 6 & 0.5 \\
\hline \multirow{4}{*}{ Weather } & Rainy & 33 & 2.7 \\
\hline & Foggy & 41 & 3.4 \\
\hline & Dry & 1121 & 92.4 \\
\hline & Cloudy & 18 & 1.5 \\
\hline \multirow{3}{*}{$\begin{array}{l}\text { Contributory } \\
\text { Factors }\end{array}$} & Human & 810 & 66.8 \\
\hline & Environmental & 92 & 7.6 \\
\hline & Vehicle & 311 & 25.6 \\
\hline \multirow{9}{*}{$\begin{array}{l}\text { Vehicle on } \\
\text { Fault }\end{array}$} & Car & 647 & 37.2 \\
\hline & Bus & 206 & 11.8 \\
\hline & Jeep & 32 & 1.8 \\
\hline & Mini Truck & 137 & 7.9 \\
\hline & Wagon & 144 & 8.3 \\
\hline & Pickup & 113 & 6.5 \\
\hline & Trailor & 166 & 9.5 \\
\hline & Truck & 266 & 15.3 \\
\hline & Info Required & 30 & 1.7 \\
\hline \multirow{9}{*}{ Severity Index } & 2009 & 0.44 & 7.6 \\
\hline & 2010 & 0.58 & 10.0 \\
\hline & 2011 & 0.75 & 12.9 \\
\hline & 2012 & 0.79 & 13.6 \\
\hline & 2013 & 0.56 & 9.6 \\
\hline & 2014 & 0.60 & 10.3 \\
\hline & 2015 & 0.42 & 7.2 \\
\hline & 2016 & 0.58 & 10.0 \\
\hline & 2017 & 1.09 & 18.7 \\
\hline
\end{tabular}




\subsection{Ranking of Black spots}

Table 3 shows the top ten black spot locations of the highway. From ten collisions prone locations two sections were found problematic based on-location problems. The topmost black spot section was at the salt range due $7 \%$ gradient and sharp horizontal curve, causing the brake failure.

Table 3. Ranking of Black spots on Highway M-2

\begin{tabular}{ccccccc}
\hline Distance from Lahore to Islamabad (km) & Fatal & Major Injuries & Minor Injuries & PDO & APW & Ranking \\
\hline 229 & 16 & 12 & 5 & 2 & 136.4 & 1 \\
223 & 7 & 9 & 6 & 2 & 74.2 & 2 \\
224 & 7 & 4 & 2 & 0 & 55.6 & 3 \\
286 & 5 & 8 & 2 & 0 & 55.6 & 3 \\
234 & 6 & 4 & 1 & 1 & 49 & 4 \\
9 & 7 & 1 & 0 & 0 & 45 & 5 \\
225 & 6 & 3 & 0 & 0 & 45 & 5 \\
350 & 5 & 3 & 2 & 2 & 41 & 6 \\
23 & 6 & 1 & 0 & 1 & 39.2 & 7 \\
195 & 5 & 2 & 1 & 0 & 36.8 & 8 \\
43 & 5 & 1 & 2 & 1 & 34.8 & 9 \\
41 & 5 & 1 & 2 & 0 & 34.6 & 10 \\
287 & 4 & 3 & 2 & 0 & 34.6 & 10 \\
\hline
\end{tabular}

Black spots were identified numerically by counting recurrences of collisions of $1 \mathrm{~km}$ section. Figure 1 shows that Collision Point Weightage (APW) was higher at two sections (one near Lahore other were Islamabad) due to illegal pedestrian and animal road crossing and highest APW value observed on salt range hilly area at $223 \mathrm{~km}, 224 \mathrm{~km}$, $225 \mathrm{~km}, 229 \mathrm{~km}$ and $234 \mathrm{~km}$ due to slope and radii curve issues, mostly road traffic collision occurred due to brake failure and vehicle slippage. The minimum APW value (34.6) of the top ten black spots has shown in Figure 1. The Ranked top ten locations as Black spot locations are shown in Table 3 and Black spot locations at each kilometer are shown in Figure 1.

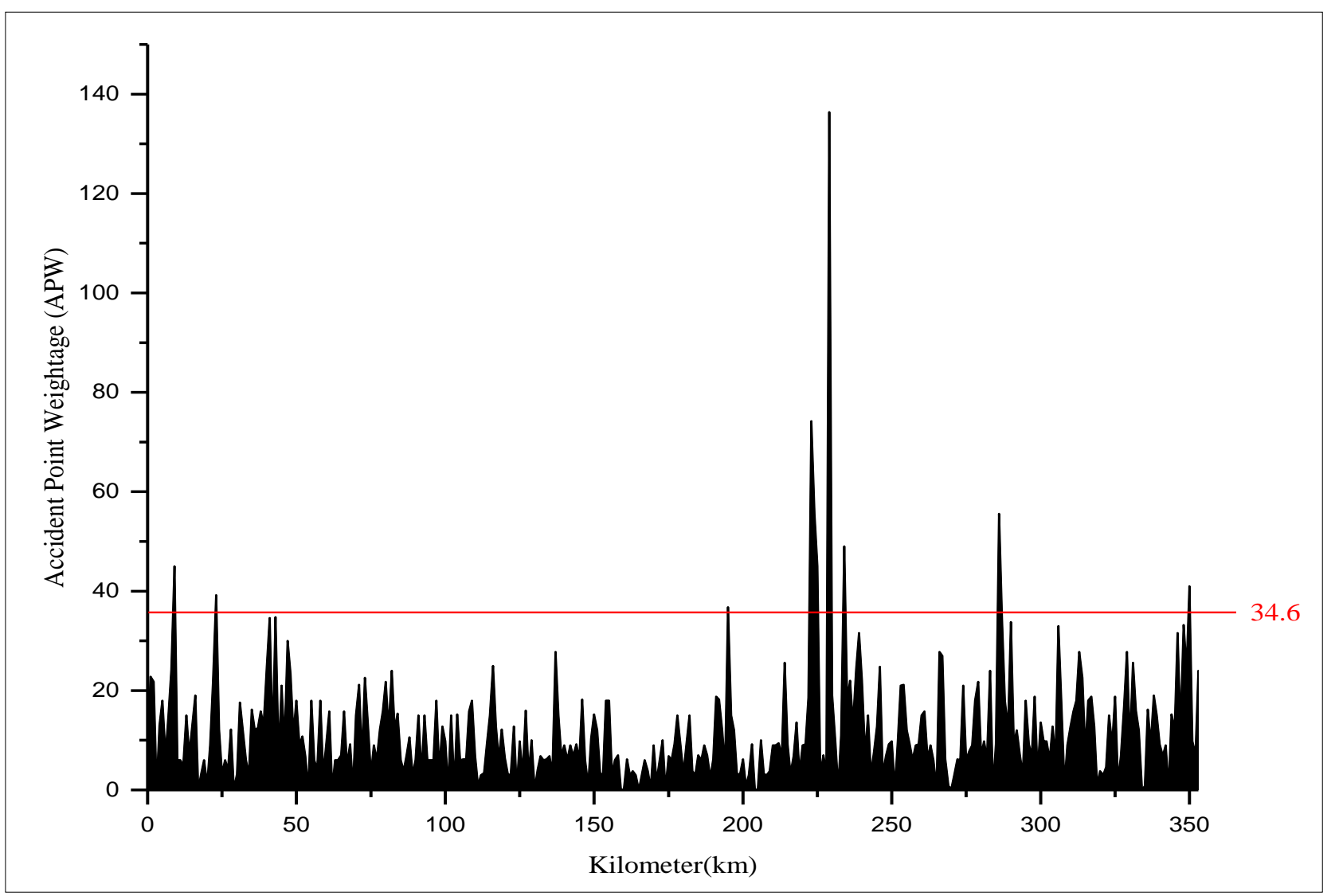

Figure 3. Black spot locations per Kilometer $(\mathrm{km})$ 


\section{Conclusion}

This research was concluded that the primary contributor in a road traffic collision was human behavior while driving the vehicle and other contributors were environment and vehicle. The number of road traffic collisions was varied giving an increase in collisions with high severity index. The road traffic collisions were higher in July and the day of Sunday as compared to other months and days. Most road traffic collisions occurred at night time as compared to day time. The road traffic collisions were higher in early morning time due to the dozing effect as compared to other times. The severity of road traffic collisions shows that fatal collisions were high as compared to others. The collision type nose to tail collisions and rollovers were highest as compared to others. The main causes of road traffic were dozing on the wheel and careless driving. Most road traffic collisions were occurred in dry weather as compared to foggy and cloudy weather. As for road geometry, highest on straight roads as compared to curve and gradient. The vehicle on fault in road traffic collisions, the passenger cars were on the fault during road traffic collisions as compared to other vehicles. The riskiest and black spot locations were identified in the salt range area. Other black spot locations were identified near to both cities' areas due to illegal pedestrian and animal crossing. Based on results and conclusions it is recommended to provide underpasses for pedestrian and animal crossings near populace area, enhance calming techniques to decrease speed on the salt range, rumble strips to reduce speed, use a seatbelt for safety, dozing alert alarm to overcome dozing, tyre inspection devices to check the condition of tyres to reduce tyre burst and the introduction of public awareness campaigns on the significance of road safety.

\subsection{Limitations of the Study}

This study was started as the case study of the Lahore-Islamabad (M-2) highway to show the analysis of traffic road collisions with black spots locations in Pakistan. Based on the study, results cannot apply for the whole country because each city has heterogeneity in terms of population behavior, traffic, and the environment.

\section{Conflicts of Interest}

The authors declare no conflict of interest.

\section{References}

[1] Ogunseitan, Oladele A. "The Asbestos Paradox: Global Gaps in the Translational Science of Disease Prevention." Bulletin of the World Health Organization 93, no. 5 (February 27, 2015): 359-360. doi:10.2471/blt.14.142307.

[2] “IRTAD.” Road Safety Annual Report 2015 (October 12, 2015): 3-3. doi:10.1787/irtad-2015-1-en.

[3] Mannering, Fred L., Venky Shankar, and Chandra R. Bhat. "Unobserved Heterogeneity and the Statistical Analysis of Highway Accident Data.” Analytic Methods in Accident Research 11 (September 2016): 1-16. doi:10.1016/j.amar.2016.04.001.

[4] Peden, M. "World Health Organization Dedicates World Health Day to Road Safety." Injury Prevention 10, no. 2 (April 1, 2004): 67-67. doi:10.1136/ip.2004.005405

[5] Ratanavaraha, Vatanavongs, and Sonnarong Suangka. "Impacts of Accident Severity Factors and Loss Values of Crashes on Expressways in Thailand.” IATSS Research 37, no. 2 (March 2014): 130-136. doi:10.1016/j.iatssr.2013.07.001.

[6] Toroyan, T. "Global Status Report on Road Safety." Injury Prevention 15, no. 4 (August 1, 2009): $286-286$. doi:10.1136/ip.2009.023697.

[7] Hordofa, Girma Gemechu, Sahilu Assegid, Abiot Girma, and Tesfaye Dagne Weldemarium. "Prevalence of Fatality and Associated Factors of Road Traffic Accidents Among Victims Reported to Burayu Town Police Stations, Between 2010 and 2015, Ethiopia.” Journal of Transport \& Health 10 (September 2018): 186-193. doi:10.1016/j.jth.2018.06.007.

[8] Sandhyavitri, Ari, Zamri, Sugeng Wiyono, and Subiantoro. "Three Strategies Reducing Accident Rates at Black Spots and Black Sites Road in Riau Province, Indonesia.” Transportation Research Procedia 25 (2017): $2153-2166$. doi:10.1016/j.trpro.2017.05.415.

[9] Omar, Noorliyana, Joewono Prasetijo, Basil David Daniel, and Mohd Asrul Effendi Abdullah. "Accident Analysis and Highway Safety." Edited by M.J. Zainorizuan, L. Yee Yong, L. Alvin John Meng Siang, O. Mohamad Hanifi, R. Siti Nazahiyah, and A. Mohd Shalahuddin. MATEC Web of Conferences 103 (2017): 08002. doi:10.1051/matecconf/201710308002.

[10] Elvik, Rune. "Road Safety Management by Objectives: A Critical Analysis of the Norwegian Approach." Accident Analysis \& Prevention 40, no. 3 (May 2008): 1115-1122. doi:10.1016/j.aap.2007.12.002.

[11] Konkor, Irenius, Moses Kansanga, Yujiro Sano, Kilian Atuoye, and Isaac Luginaah. "Risk-Taking Behaviours and Timing to First Motorbike Collision in the Upper West Region of Ghana." Journal of Transport \& Health 12 (March 2019): 105-114. doi:10.1016/j.jth.2019.01.001. 
[12] Prassas, Elena S., and Roger P. Roess. "Engineering Economics and Finance for Transportation Infrastructure.” Springer Tracts on Transportation and Traffic (2013). doi:10.1007/978-3-642-38580-3.

[13] Noyce, David A. "Review of Traffic and Highway Engineering, Fourth Edition, by Nicholas J. Garber and Lester A. HoelTraffic and Highway EngineeringCENGAGE Learning\$160." Journal of Transportation Engineering 135, no. 4 (April 2009): 250-251. doi:10.1061/(asce)0733-947x(2009)135:4(250).

[14] Gokhale, D. V. "The Minimum Discrimination Information Analysis of Contingency Tables in Traffic Safety Studies." Contingency Table Analysis for Road Safety Studies (1981): 85-105. doi:10.1007/978-94-009-8597-1_6.

[15] Singh, Sanjay Kumar. "Road Traffic Accidents in India: Issues and Challenges.” Transportation Research Procedia 25 (2017): 4708-4719. doi:10.1016/j.trpro.2017.05.484.

[16] Rolison, Jonathan J., Shirley Regev, Salissou Moutari, and Aidan Feeney. "What Are the Factors That Contribute to Road Accidents? An Assessment of Law Enforcement Views, Ordinary Drivers' Opinions, and Road Accident Records." Accident Analysis \& Prevention 115 (June 2018): 11-24. doi:10.1016/j.aap.2018.02.025.

[17] Nikhil.T.R, Nikhil.T.R, Harish J Kulkarni, and Sarvada H Sarvada H. "Identification of Black Spots and Improvements to Junctions in Bangalore City." International Journal of Scientific Research 2, no. 8 (June 1, 2012): 136-139. doi:10.15373/22778179/aug2013/46.

[18] Ma, Weihong, and Zhenzhou Yuan. "Analysis and Comparison of Traffic Accident Regression Prediction Model.” 3rd International Conference on Electromechanical Control Technology and Transportation (2018). doi:10.5220/0006970803640369.

[19] "Pakistan - Government.” Foreign Law Guide (2020). doi:10.1163/2213-2996_flg_com_323848.

[20] “Transport Infrastructure” (March 22, 2016). doi:10.1787/eco_surveys-pol-2016-graph22-en.

[21] Anwaar, Ahmed, Panagiotis Anastasopoulos, Ghim Ping Ong, Samuel Labi, and Mouyid Bin Islam. "Factors Affecting Highway Safety, Health Care Services, and Motorization-An Exploratory Empirical Analysis Using Aggregate Data." Journal of Transportation Safety \& Security 4, no. 2 (June 2012): 94-115. doi:10.1080/19439962.2011.619372.

[22] Younis, Muhammad Waqas, Zahara Batool, Murtaza Bukhari, Zia ur Rehman, Saqib Shahzad, Atteq ur Rehman, Ammad Hassan Khan, Mazhar Yasin, Muhammad Irfan, and Muhammad Sarmad Ali. "Pattern of Underreporting of Road Traffic Injuries (RTIs): An Investigation of Missing Burden of RTIs in Pakistan.” Journal of Transport \& Health 14 (September 2019): 100575. doi:10.1016/j.jth.2019.100575.

[23] Tahir, Muhammed Navid. "Road Safety Aspects of Motorcycle Rickshaws in Pakistan" (2018). doi: 10.5204/thesis.eprints. 115467.

[24] “Road Traffic Injury Accidents.” ITF Transport Outlook 2013 (December 10, 2013). doi:10.1787/9789282103937-table71-en.

[25] Sandhu, H. A. S., Gyanendra Singh, M. S. Sisodia, and Rajiv Chauhan. "Identification of Black Spots on Highway with Kernel Density Estimation Method.” Journal of the Indian Society of Remote Sensing 44, no. 3 (February 3, 2016): $457-464$. doi:10.1007/s12524-015-0500-2.

[26] Subhra Konar, Tuhin. "Applicability of Caline4 Model for Nox in Kolkata Roadway.” Journal of Civil \& Environmental Engineering 01, no. S1 (2013). doi:10.4172/2165-784x.s1-005.

[27] Bagheri Ramiani, Masoud, and Gholamreza Shirazian. "Ranking and Determining the Factors Affecting the Road Freight Accidents Model.” Civil Engineering Journal 6, no. 5 (May 1, 2020): 928-944. doi:10.28991/cej-2020-03091518. 